\title{
The Caenorhabditis elegans Argonautes ALG-1 and ALG-2: Almost Identical yet Different
}

\author{
B.B.J. Tops, R.H.A. Plasterk, AND R.F. KetTing \\ Hubrecht Laboratory, Utrecht, The Netherlands
}

\begin{abstract}
Since the discovery of the RNA interference pathway, several other small RNA pathways have been identified. These make use of the same basic machinery to generate small RNA molecules that can direct different types of (post)transcriptional silencing. The specificity for the different silencing pathways (which type of silencing a small RNA initiates) is likely accomplished by the effector molecules that bind the small RNAs: the Argonaute proteins. Two Argonaute proteins, ALG-1 and ALG-2, have been implicated in one of the silencing pathways, the microRNA (miRNA) pathway, in Caenorhabditis elegans. The two proteins are highly similar, and previous work suggested redundancy of the two proteins. Here, we present genetic and biochemical data that hint at individual nonredundant functions for ALG-1 and ALG-2 in the processing of precursor miRNAs to mature miRNAs.
\end{abstract}

RNA interference (RNAi) is a mechanism that degrades mRNAs in a sequence-specific manner (Fire et al. 1998). Since its discovery in C. elegans, identical mechanisms have been discovered in fungi, plants, flies, and mammals. One of the functions of this mechanism is to protect the genome from selfish nucleic acids, such as viruses and transposons (for review, see Plasterk 2002). Besides this posttranscriptional gene-silencing mechanism that functions by degrading the mRNAs, similar mechanisms exist that function through translational repression of mRNAs or by regulating gene silencing at the transcriptional level by heterochromatin modifications. All of these posttranscriptional and transcriptional silencing mechanisms are identical in that they require (1) small RNAs to provide the necessary sequence specificity and (2) effector molecules: Argonaute proteins that bind the small RNAs.

Depending on the type of silencing pathway, different small RNAs are distinguished. Small RNAs functioning in the RNAi pathway and directing mRNA degradation are termed small interfering RNAs (siRNAs) (Hamilton and Baulcombe 1999; Zamore et al. 2000), and small RNAs derived from RNA hairpins encoded by the genome and directing mRNA translational repression, and/or degradation, are named microRNAs (Lau et al. 2001; Ambros et al. 2003). siRNAs and miRNAs are both single-stranded RNA (ssRNA) molecules of approximately 21-23 nucleotides (depending on the organism) that are generated from longer double-stranded RNAs (dsRNAs) by the Dicer enzyme (Bernstein et al. 2001; Grishok et al. 2001; Hutvagner et al. 2001; Ketting et al. 2001). The source of the dsRNA differs for each of the silencing pathways, including viral RNA, readthrough transcripts from transposons or genomeencoded snap-back structures. In addition to these two wellstudied small RNAs, other small RNA species have recently been identified: repeat-associated siRNAs (rasi's) (Aravin et al. 2003) and Piwi-associated RNAs (piRNAs) (Aravin et al. 2006; Girard et al. 2006). Neither the biogenesis nor function of these small RNAs is known.
The Argonaute proteins are the effector molecules in the different silencing pathways and are characterized by a PAZ and PIWI domain. The first is involved in binding of the small RNAs (Lingel et al. 2003; Song et al. 2003; Yan et al. 2003) and the latter resembles an RNase $\mathrm{H}$ motif that also binds the $5^{\prime}$ phosphate of the small RNAs and is required for cutting the targeted mRNA (Parker et al. 2004; Rand et al. 2004; Song et al. 2004). However, not all Argonaute proteins contain the conserved DDH motif required for this nuclease activity, so presumably not all Argonautes are cleaving mRNAs.

One of the silencing pathways is the miRNA pathway. Here we focus on miRNA function in animal systems. Long RNA transcripts are transcribed from the genome that can snap back on themselves (primary miRNA or pri-miRNA) and are processed into approximately 70-nucleotide stemloop structures (precursors miRNA or pre-miRNA) by Drosha in the nucleus (Lee et al. 2003). The pre-miRNA serves as a template for Dicer which processes the premiRNA into the double-stranded miRNA of about 21 nucleotides (Bernstein et al. 2001; Grishok et al. 2001; Hutvagner et al. 2001; Ketting et al. 2001). This miRNA is subsequently unwound, and the single-stranded mature miRNA, bound by an Argonaute, can hybridize to the 3'UTR (untranslated region) of a cognate mRNA. In general, this will lead to translational inhibition without direct degradation of the messenger by the Argonaute.

One of the questions that remains is how a small RNA is directed to a specific silencing pathway (e.g., transcriptional silencing, mRNA degradation, or blocking translation). Since the small RNAs for the different silencing pathways are generated by the same proteins, the most obvious solution would be to have different effector molecules (Argonautes) for different silencing pathways, depending on the source of the dsRNA; for example, a short RNA hairpin in the case of miRNAs or a larger intermolecular dsRNA in the case of viral siRNAs.

Indeed, the genomes of most eukaryotic organisms encode several Argonautes. The C. elegans genome 
encodes 27 Argonaute family members of which some have indeed been implicated in different silencing processes. Two of these, ALG-1 and ALG-2, have been implicated in the miRNA pathway (Grishok et al. 2001). Although both Argonautes contain the DDH motif in their PIWI domain and should therefore be capable of cutting the targeted mRNA, ALG-1 and ALG-2 appear to be associated with miRNAs that block translation, although this may be the consequence of the imperfect matching between miRNA and mRNA (Hutvagner and Zamore 2002). Interestingly, although the two proteins share $88 \%$ identity at the protein level, the knockout phenotypes of the two genes differ remarkably. Mutant alleles of alg- 1 (gk214 \& tm 492) and alg-1(RNAi) animals appear to be viable, but they display a range of phenotypes resulting in very sick animals (Grishok et al. 2001; M. Jovanovic, pers. comm.). $\operatorname{alg}-1(g k 214)$ may be a hypomorphic allele since it only deletes part of the amino terminus, but alg-1(tm492) is likely a null, because it deletes the whole PAZ domain and leads to an early stop. Additionally, a lac $Z$ reporter under the translational control of the let-7 miRNA is de-silenced in alg-1 (RNAi) animals (Caudy et al. 2003). This is in contrast to the alg-2(ok304) mutant which shows minor phenotypes at best and does not de-silence the lac $Z$ reporter either (Grishok et al. 2001; results not shown). alg-1/2 double mutants are lethal (Grishok et al. 2001; this paper), indicating that these genes may act in a redundant way. However, here we describe genetic and biochemical studies which suggest that ALG-1 and ALG-2 may well carry out specific, nonredundant tasks.

\section{MATERIALS AND METHODS}

General methods. The Bristol N2 strain was used as standard wild-type strain. NL4511 and NL4517 (alg-1:: $H A$ and $\operatorname{alg}-2: \because H A$, respectively) were generated using standard microinjection and integration techniques. VC446 and WM53 were obtained from the Caenorhabditis Genetics Center. Dicer assays (Ketting et al. 2001), extract preparation, western blotting ( $\alpha \mathrm{HA}$, clone 12CA5 from Sigma), immunoprecipitations ( $\alpha \mathrm{HA}$-matrix, clone 3F10 from Roche Applied Sciences), and size-fractionation experiments were carried out as described previously (Tops et al. 2005).

Gel-shift assay. Gel-shift assays were performed using a radioactive $5^{\prime}$-phosphate-labeled synthetic pre-let-7 (C. elegans and human sequence) (Proligo). Gel shifts were performed for 5 minutes on ice in $10 \mathrm{~mm}$ Tris at $\mathrm{pH} 7.0$, $10 \mathrm{mM} \mathrm{MgCl}_{2}, 1 \mathrm{~mm}$ dithiothreitol (DTT), $125 \mathrm{ng} / \mu \mathrm{l}$ yeast tRNA, $1 \mathrm{~mm}$ ATP, and 6\% PEG-8000 using C. elegans embryonic extracts. Reactions were run on a $5 \%$ nondenaturing gel at $4^{\circ} \mathrm{C}$.

\section{GENETICS}

We performed a genome-wide synthetic lethal screen for both the alg-1 (gk214) and alg-2(ok304) mutant strains by RNAi, using the Ahringer RNAi library (Kamath et al. 2003; van Haaften et al. 2004), hoping to identify genes
Table 1. Genes Causing Synthetic Lethality When Knocked Down by RNAi in an alg-1 (gk214) or alg-2(ok304) Genetic Background

\begin{tabular}{|c|c|c|}
\hline Cosmid & Gene & Description \\
\hline \multicolumn{3}{|c|}{ Synthetic lethal with alg-1(gk214) } \\
\hline T07D3.7 & alg-2 & $\begin{array}{l}\text { Argonaute involved in miRNA } \\
\text { pathway in C. elegans }\end{array}$ \\
\hline $\mathrm{C} 25 \mathrm{~A} 1.5$ & & cytochrome $b_{5}$ domain \\
\hline $\mathrm{C} 25 \mathrm{~A} 1.6$ & & H/ACA snoRNP complex \\
\hline T04D3.2 & $s d z-30$ & unknown \\
\hline Y47G6A.19 & & zinc carboxypeptidase domain \\
\hline F52C6.3 & phi-32 & ubiquitin-like protein \\
\hline B0286.4 & $n t l-2$ & CCR4/NOT complex component \\
\hline F44B9.7 & pqn-38 & replication factor $\mathrm{C}$ domain \\
\hline F29B9.6 & $u b c-9$ & E2 ubiquitin-conjugating enzyme \\
\hline \multicolumn{3}{|c|}{ Synthetic lethal with alg-2(ok304) } \\
\hline C35C5.1 & $s d c-2$ & $\begin{array}{l}\text { involved in C. elegans dosage } \\
\text { compensation }\end{array}$ \\
\hline F44A6.2 & $\operatorname{sex}-1$ & $\begin{array}{l}\text { involved in } C \text {. elegans dosage } \\
\text { compensation }\end{array}$ \\
\hline F48F7.1 & $\operatorname{alg}-1$ & $\begin{array}{l}\text { Argonaute involved in miRNA } \\
\text { pathway in } C \text {. elegans }\end{array}$ \\
\hline ZK262.8 & & C. elegans-specific \\
\hline
\end{tabular}

involved in miRNA biogenesis or genes involved in essential pathways regulated by miRNAs. If both proteins have similar functions and are indeed functionally redundant, we expected to find similar results for the two mutants. This is, however, not what we find. There is no overlap in the genes that cause lethality when knocked down in the alg-1 (gk214) background and those causing lethality in the alg-2(ok304) background (Table 1). The genes found to be synthetic lethal with alg-1 (gk214) must be interpreted with caution since $a l g-1$ ( $g k 214)$ animals are already very sick. However, the genes reproducibly causing lethality in an alg-2(ok304) background certainly do not cause synthetic lethality in an alg-1 (gk214) background when specifically retested. Interestingly, two of the genes identified are involved in the dosage compensation/sex determination pathway in C. elegans and suggest an involvement of miRNAs in the dosage compensation pathway (B.B.J. Tops et al., in prep.). The observation that there is no overlap between the genes causing synthetic lethality in $a l g-1(g k 214)$ and alg-2(ok304) animals suggests that despite their high level of amino acid sequence identity, there are specific nonredundant functions for the two Argonaute proteins.

\section{BIOCHEMISTRY}

To test whether the differences between the alg- 1 and alg-2 synthetic lethal screens could be explained by a difference in temporal or differential expression between the two Argonautes, we generated transgenic ALG-1::HA and ALG-2::HA expressing lines driven by an alg- 1 and alg-2 promoter, respectively, and performed immunostainings on these animals. ALG-1 (result not shown) and ALG-2 are expressed in the cytoplasm from early embryogenesis (Fig. 1) to adulthood (result not shown) in most, if not all, cells in C. elegans, and there is no clear difference in the expression patterns of the two proteins. This appears to 


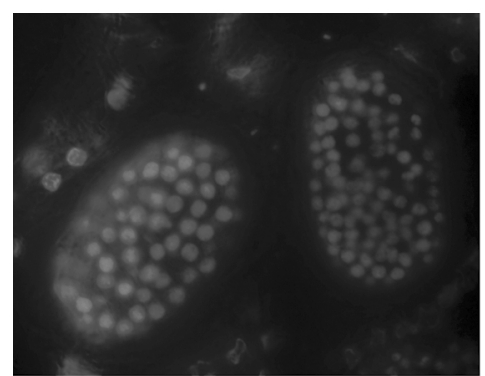

DAPI

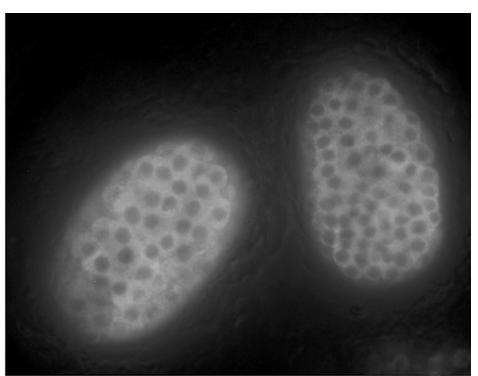

$\alpha \mathrm{HA}$
Figure 1. Subcellular localization of ALG-2. alg-2::HA transgenic embryos were stained with DAPI and monoclonal $\alpha \mathrm{HA}$ antibodies. Only cytoplasmic staining is observed. exclude the possibility that the observed genetic differences stem from a difference in expression pattern.

A second explanation for nonredundant functions for ALG-1 and ALG-2 could be that both Argonautes bind different subsets of miRNAs. Analysis of the miRNAs associated with ALG-1 and ALG-2 by immunoprecipitation of the HA-tagged proteins and subsequent analysis of the associated RNAs on microarrays show that there is no difference in miRNAs pulled down with ALG-1 or ALG-2 (B.B. Tops et al., in prep.), suggesting that this also is not likely to be the explanation for ALG-1- and ALG-2-specific functions.

A third explanation is that the two Argonautes associate with different proteins, resulting in different complexes with specialized functions. To test this, we size-fractionated the ALG-1- and ALG-2-containing complexes. As shown in Figure 2, in embryonic cytosolic extracts ALG-2 resides in two distinct complexes of approximately 250 and $500 \mathrm{kD}$. This is in contrast to ALG-1, which migrates in a single complex larger than $650 \mathrm{kD}$. When analyzed for mir-40 (Fig. 2) or mir-52 (result not shown), most of these miRNAs reside in the low-molecular-weight complex of ALG-2, and only a small fraction is comigrating with ALG-1. These data demonstrate that both Argonautes indeed reside in different complexes.

Both ALG-1 and ALG-2 have been implicated in the processing of pre-miRNAs to mature miRNAs. In the absence of one or both of the Argonaute proteins, less of the mature lin-4 miRNA is detected in vivo, and the pre-
miRNA accumulates as it does in $d c r-1(R N A i)$ animals (Grishok et al. 2001). The same is true for the let-7 miRNA, although accumulation of the pre-miRNA is less distinct. Purified recombinant Dicer enzyme is capable of processing pre-miRNA, so biochemically, it is unlikely that ALG-1 or ALG-2 is directly involved in generating miRNAs. So why do these mutants accumulate premiRNAs? A possible explanation is based on experiments performed using human cell lines (Chendrimada et al. 2005; Gregory et al. 2005). From these experiments, it was concluded that the processing of pre-miRNAs into miRNAs and the loading of the miRNAs into the RNAinduced silencing complex (RISC), containing AGO2, is a coupled process. Thus, an alternative explanation for the observed accumulation of pre-miRNAs in alg- 1 and $a l g-2$ mutant animals is not that these animals are not capable of processing the pre-miRNA, but that they are unable to load the processed miRNA into the silencing complex and thereby unable to release the Dicer enzyme for a new round of pri-miRNA processing.

To study the processing of pre-miRNAs to miRNAs in C. elegans and the involvement of ALG-1 and ALG-2, we generated cytosolic extracts from $\operatorname{alg}-1(g k 214)$, alg-2(ok304), and wild-type animals and tested these for in vitro pre-let-7 processing. Wild-type extract nicely processes a synthetic pre-let-7 into its mature form. Although we have looked carefully, we have never seen any association of in vitro processed miRNAs with proteins, either by gel-shift analysis or by size fractionation (results not shown). These experi-
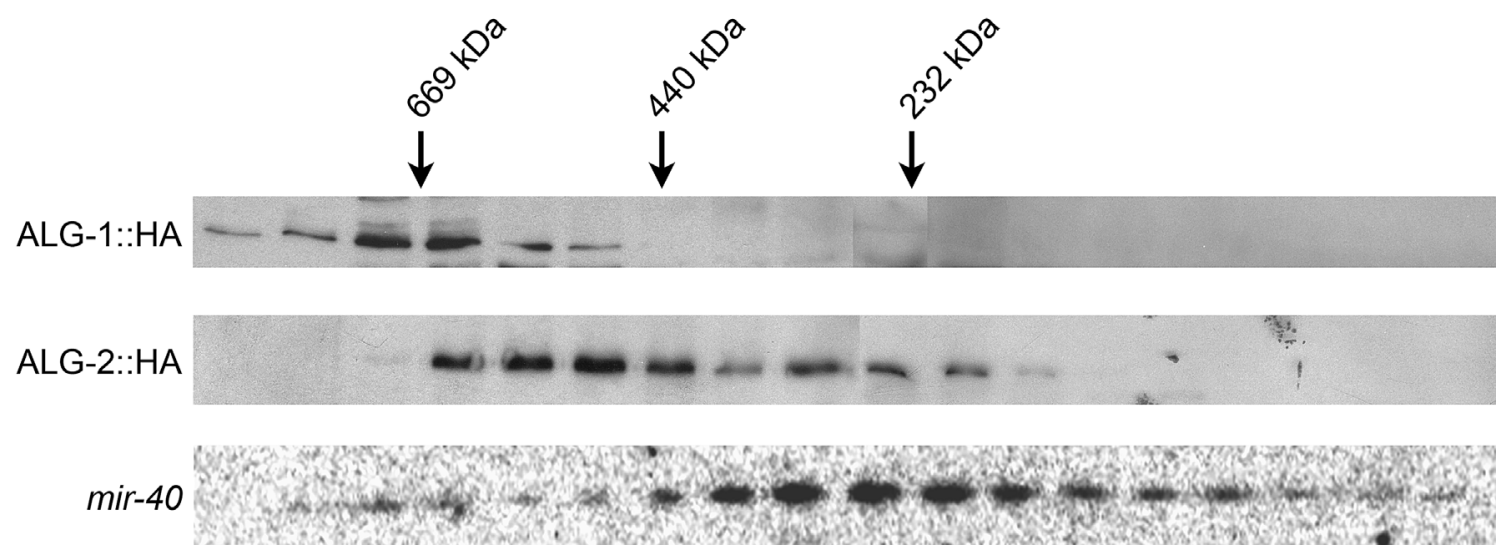

Figure 2. Size fractionation of ALG-1- and ALG-2-containing complexes. Extracts from alg-1::HA and alg-2::HA transgenic embryos were size-fractionated on a superdex $200 \mathrm{HR}$ 10/30 column, and fractions were analyzed by western blotting using monoclonal $\alpha \mathrm{HA}$ antibodies and northern blotting using mir-40 and mir-52 probes. 

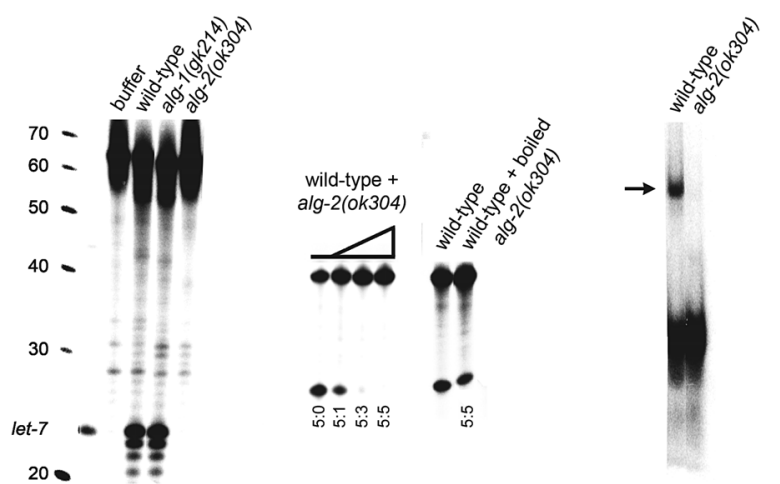

Figure 3. In vitro processing of pre-let-7 RNA. In vitro processing of pre-let-7 in buffer and embryonic extracts of wildtype, alg-1 (gk214), or alg-2(ok304) animals (left). Mixing of wild-type and alg-2(ok304) embryonic extracts with and without boiling of the alg-2(ok304) extract. Wild-type:alg-2(ok304) mixing ratios are indicated (middle). Gel-shift assay of the synthetic pre-let-7 with wild-type and alg-2(ok304) extract. Arrow indicates the shifted pre-let-7 (shifted band only contains prelet-7 as analyzed by denaturing urea gel) (right).

ments indicate that processed miRNAs are released from the Dicer complex, indicating that this in vitro system only measures pre-miRNA processing and miRNA release but not RISC loading.

Next, we analyzed the activity of our mutant extracts. Extract prepared from alg-2(ok304) animals is completely deficient in pre-let-7 processing, recapitulating the observed in vivo data, although the in vitro effect is more pronounced. This is in contrast to the alg-1 (gk214) extract that processes the pre-let-7 normally (Fig. 3, left). We then tested whether we could reconstitute the processing activity in alg-2(ok304) extract by mixing in wild-type extract. To our surprise, we could not: The alg2 extract has a dominant-negative effect on the processing activity in wild-type extracts (Fig. 3, middle). We could eliminate this inhibitory effect by boiling the alg-2 extract, suggesting that the inhibitor is probably a protein and not a nucleic acid (Fig. 3, middle).

This dominant-negative effect may be explained by recent data suggesting that different silencing pathways compete for similar limiting (co)factors. Dicer was shown to interact with proteins acting in the endogenous RNAi pathway (dsRNAs generated by the host), exogenous RNAi pathway (dsRNA from the environment, e.g., viruses), and miRNA pathway. Inactivation of one pathway leads to hyperactivation of the other, suggesting that the limiting factor for these pathways is probably Dicer itself (Simmer et al. 2002; Kennedy et al. 2004; Duchaine et al. 2006; Lee et al. 2006). In extracts lacking ALG-2, cofactors normally associated with this Argonaute to generate miRNAs may still be present and bind to Dicer, somehow blocking its activity (Fig. 4). As Dicer is the limiting factor, ALG-2 mutant extract will harbor enough inhibitor to also block Dicer protein molecules from a wild-type extract. In support of this model, not only pre-miRNA processing is blocked in alg-2 mutant extract, but also the processing of long dsRNAs ( $\sim 300$ nucleotides) that are typically used in RNAi is impaired (results not shown).

The observed differences between alg-1 and alg-2 extracts regarding pre-let-7 processing activity may well reflect a functional difference between the two Argonaute proteins. ALG-2 may be involved in the biogenesis of miRNAs by loading the pre-miRNA in the Dicer complex and/or by facilitating the release of the processed miRNA. To test this, we performed a gel-shift assay with the synthetic pre-let-7. Both wild-type extract (Fig. 3, right) and $\operatorname{alg-1}(g k 214)$ (result not
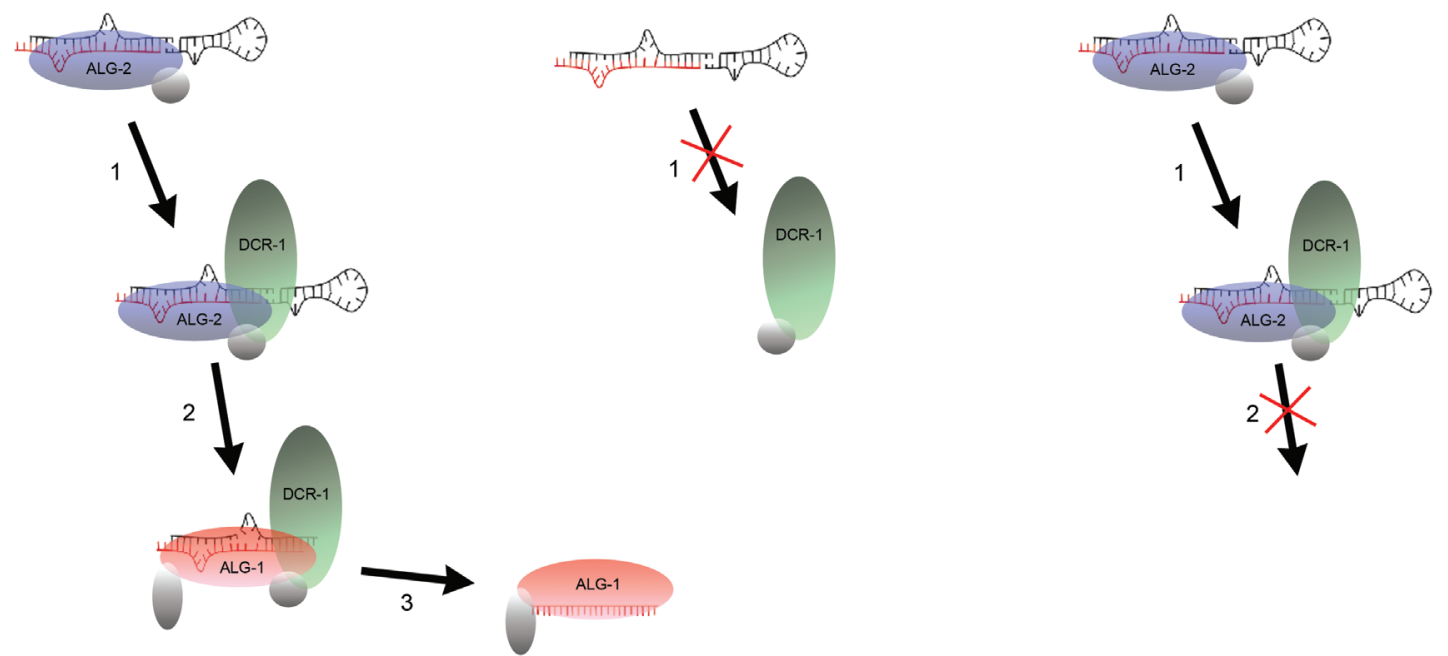

Figure 4. Model explaining the observed in vivo and in vitro data regarding alg- 1 and alg-2 in miRNA biogenesis. ALG-2 facilitates in loading the pre-miRNA in the Dicer complex (1). C. elegans Dicer (DCR-1) processes the pre-miRNA to the double-stranded mature miRNA and ALG-2 facilitates loading the miRNA to ALG-1 (2). The mature miRNA/ALG-1 complex is released and can direct translational repression (3). In the absence of ALG-2, Dicer is unable to recognize and process the pre-miRNA. Additionally, ALG-2/Dicer-specific cofactors may bind to Dicer, preventing Dicer from associating with bona fide protein complexes, resulting in dominant inhibition of Dicer. In the absence of ALG-1, ALG-2 is unable to release its miRNA, resulting in saturation and eventually blocking of Dicer activity in vivo. In vitro stable association of ALG-2 and the double-stranded miRNA does not occur, guaranteeing continued pre-miRNA processing also in the absence of ALG-1. 
shown) are capable of forming a ribonucleoprotein (RNP) complex with the pre-let-7, in contrast to the alg2(ok304) extract that shows no affinity for pre-let-7 at all. This suggests that ALG-2 functions in pre-miRNA processing by loading the pre-miRNA in the Dicer complex. Since ALG-2 also binds processed miRNAs, it may also facilitate the release of the processed miRNA by Dicer and/or removing the passenger strand of the miRNA, analogous to the situation in Drosophila, where it was shown that RISC loading depends on AGO2 slicer activity (Matranga et al. 2005; Miyoshi et al. 2005). ALG-1 could act further downstream by accepting the single-stranded miRNAs from an ALG-2 complex and inhibiting translation by binding to target mRNAs. This hypothesis fits with the observed data in that alg-1 and alg-2 mutant animals would both accumulate pre-let-7 in vivo, either because Dicer is unable to form a processing complex with the pre-miRNA or because Dicer is unable to release the processed miRNA in the absence of ALG-1. In vitro, this would lead to alg-2 mutant extracts that lack Dicer activity for the same reason as the in vivo situation (Fig. 4), but alg-1 mutant extracts would still be capable of pre-miRNA processing since our in vitro system does not properly carry out the transfer of miRNAs from Dicer/ALG-2 to ALG-1 (RISC loading, see above). As the mature miRNAs do not remain stably associated with ALG-2 either, Dicer activity will not be inhibited.

Whatever the exact mechanism, it is likely that ALG-1 and ALG-2 have different functions. This does not exclude the fact that they can partially carry out each others function, but in a wild-type situation, both proteins most likely act at their specific step in the miRNA pathway. The C. elegans genome encodes 27 Argonaute proteins, and the functions of most are still unknown. However, specialized functions for different family members have been reported. Besides ALG-1 and ALG-2 that act in the miRNA pathway, RDE-1 is involved in RNAi in soma and germ line, PPW-1 seems only involved in RNAi in the germ line, and PPW-2 is involved in silencing repetitive elements: transposons and high-copy transgenic arrays (Tabara et al. 1999; Grishok et al. 2001; Tijsterman et al. 2002; Vastenhouw et al. 2003; Robert et al. 2005). Some of these specialized functions may be due to differences in temporal and/or spatial expression of the different Argonautes, but some of the differences are likely to be caused by associated proteins. Although the homology between the different family members is high, largely due to the high conservation of the PAZ and PIWI domains, the long amino-terminal tail of the Argonautes is highly diverged between different proteins and could serve as a specific site of interaction for additional proteins. Now that the similarities between the different small RNA pathways are recognized, it will be of great interest to investigate these differences.

\section{ACKNOWLEDGMENTS}

This research was supported by a ZonMW/TOP grant to R.H.A.P. and a VIDI grant to R.F.K., both supplied by the Dutch Organization for Scientific research (NWO).

\section{REFERENCES}

Ambros V., Bartel B., Bartel D.P., Burge C.B., Carrington J.C., Chen X., Dreyfuss G., Eddy S.R., Griffiths-Jones S., Marshall M., et al. 2003. A uniform system for microRNA annotation. RNA 9: 277.

Aravin A.A., Lagos-Quintana M., Yalcin A., Zavolan M., Marks D., Snyder B., Gaasterland T., Meyer J., and Tuschl T. 2003. The small RNA profile during Drosophila melanogaster development. Dev. Cell 5: 337.

Aravin A., Gaidatzis D., Pfeffer S., Lagos-Quintana M., Landgraf P., Iovino N., Morris P., Brownstein M.J., KuramochiMiyagawa S., Nakano T., et al. 2006. A novel class of small RNAs bind to MILI protein in mouse testes. Nature 442: 203.

Bernstein E., Caudy A.A., Hammond S.M., and Hannon G.J. 2001. Role for a bidentate ribonuclease in the initiation step of RNA interference. Nature 409: 363.

Caudy A.A., Ketting R.F., Hammond S.M., Denli A.M., Bathoorn A.M., Tops B.B., Silva J.M., Myers M.M., Hannon G.J., and Plasterk R.H. 2003. A micrococcal nuclease homologue in RNAi effector complexes. Nature 425: 411.

Chendrimada T.P., Gregory R.I., Kumaraswamy E., Norman J., Cooch N., Nishikura K., and Shiekhattar R. 2005. TRBP recruits the Dicer complex to Ago 2 for microRNA processing and gene silencing. Nature 436: 740.

Duchaine T.F., Wohlschlegel J.A., Kennedy S., Bei Y., Conte D., Jr., Pang K., Brownell D.R., Harding S., Mitani S., Ruvkun G., et al. 2006. Functional proteomics reveals the biochemical niche of $C$. elegans DCR-1 in multiple smallRNA-mediated pathways. Cell 124: 343.

Fire A., Xu S., Montgomery M.K., Kostas S.A., Driver S.E., and Mello C.C. 1998. Potent and specific genetic interference by double-stranded RNA in Caenorhabditis elegans. Nature 391: 806

Girard A., Sachidanandam R., Hannon G.J., and Carmell M.A. 2006. A germline-specific class of small RNAs binds mammalian Piwi proteins. Nature 442: 199.

Gregory R.I., Chendrimada T.P., Cooch N., and Shiekhattar R. 2005. Human RISC couples microRNA biogenesis and posttranscriptional gene silencing. Cell 123: 631.

Grishok A., Pasquinelli A.E., Conte D., Li N., Parrish S., Ha I., Baillie D.L., Fire A., Ruvkun G., and Mello C.C. 2001. Genes and mechanisms related to RNA interference regulate expression of the small temporal RNAs that control C. elegans developmental timing. Cell 106: 23.

Hamilton A.J. and Baulcombe D.C. 1999. A species of small antisense RNA in posttranscriptional gene silencing in plants. Science 286: 950.

Hutvagner G. and Zamore P.D. 2002. A microRNA in a multipleturnover RNAi enzyme complex. Science 297: 2056.

Hutvagner G., McLachlan J., Pasquinelli A.E., Balint E., Tuschl T., and Zamore P.D. 2001. A cellular function for the RNAinterference enzyme Dicer in the maturation of the let-7 small temporal RNA. Science 293: 834.

Kamath R.S., Fraser A.G., Dong Y., Poulin G., Durbin R., Gotta M., Kanapin A., Le Bot N., Moreno S., Sohrmann M., et al. 2003. Systematic functional analysis of the Caenorhabditis elegans genome using RNAi. Nature 421: 231.

Kennedy S., Wang D., and Ruvkun G. 2004. A conserved siRNA-degrading RNase negatively regulates RNA interference in C. elegans. Nature 427: 645.

Ketting R.F., Fischer S.E., Bernstein E., Sijen T., Hannon G.J., and Plasterk R.H. 2001. Dicer functions in RNA interference and in synthesis of small RNA involved in developmental timing in C. elegans. Genes Dev. 15: 2654.

Lau N.C., Lim L.P., Weinstein E.G., and Bartel D.P. 2001. An abundant class of tiny RNAs with probable regulatory roles in Caenorhabditis elegans. Science 294: 858.

Lee R.C., Hammell C.M., and Ambros V. 2006. Interacting endogenous and exogenous RNAi pathways in Caenorhabditis elegans. RNA 12: 589.

Lee Y., Ahn C., Han J., Choi H., Kim J., Yim J., Lee J., Provost P., Radmark O., Kim S., and Kim V.N. 2003. The nuclear RNase III Drosha initiates microRNA processing. Nature 425: 415. 
Lingel A., Simon B., Izaurralde E., and Sattler M. 2003. Structure and nucleic-acid binding of the Drosophila Argonaute 2 PAZ domain. Nature 426: 465.

Matranga C., Tomari Y., Shin C., Bartel D.P., and Zamore P.D. 2005. Passenger-strand cleavage facilitates assembly of siRNA into Ago2-containing RNAi enzyme complexes. Cell 123: 607 .

Miyoshi K., Tsukumo H., Nagami T., Siomi H., and Siomi M.C. 2005. Slicer function of Drosophila Argonautes and its involvement in RISC formation. Genes Dev. 19: 2837.

Parker J.S., Roe S.M., and Barford D. 2004. Crystal structure of a PIWI protein suggests mechanisms for siRNA recognition and slicer activity. EMBO J. 23: 4727.

Plasterk R.H. 2002. RNA silencing: The genome's immune system. Science 296: 1263.

Rand T.A., Ginalski K., Grishin N.V., and Wang X. 2004. Biochemical identification of Argonaute 2 as the sole protein required for RNA-induced silencing complex activity. Proc. Natl. Acad. Sci. 101: 14385.

Robert V.J., Sijen T., van Wolfswinkel J., and Plasterk R.H. 2005. Chromatin and RNAi factors protect the C. elegans germline against repetitive sequences. Genes Dev. 19: 782.

Simmer F., Tijsterman M., Parrish S., Koushika S.P., Nonet M.L., Fire A., Ahringer J., and Plasterk R.H. 2002. Loss of the putative RNA-directed RNA polymerase RRF-3 makes $C$. elegans hypersensitive to RNAi. Curr. Biol. 12: 1317.

Song J.J., Smith S.K., Hannon G.J., and Joshua-Tor L. 2004. Crystal structure of Argonaute and its implications for RISC slicer activity. Science 305: 1434.

Song J.J., Liu J., Tolia N.H., Schneiderman J., Smith S.K., Martienssen R.A., Hannon G.J., and Joshua-Tor L. 2003. The crystal structure of the Argonaute2 PAZ domain reveals an RNA binding motif in RNAi effector complexes. Nat. Struct. Biol. 10: 1026.

Tabara H., Sarkissian M., Kelly W.G., Fleenor J., Grishok A., Timmons L., Fire A., and Mello C. 1999. The rde-1 gene, RNA interference, and transposon silencing in C. elegans. Cell 99: 123.

Tijsterman M., Okihara K.L., Thijssen K., and Plasterk R.H. 2002. PPW-1, a PAZ/PIWI protein required for efficient germline RNAi, is defective in a natural isolate of $C$. elegans. Curr. Biol. 12: 1535.

Tops B.B., Tabara H., Sijen T., Simmer F., Mello C.C., Plasterk R.H., and Ketting R.F. 2005. RDE-2 interacts with MUT-7 to mediate RNA interference in Caenorhabditis elegans. Nucleic Acids Res. 33: 347.

van Haaften G., Vastenhouw N.L., Nollen E.A., Plasterk R.H., and Tijsterman M. 2004. Gene interactions in the DNA damage-response pathway identified by genome-wide RNAinterference analysis of synthetic lethality. Proc. Natl. Acad. Sci. 101: 12992.

Vastenhouw N.L., Fischer S.E., Robert V.J., Thijssen K.L., Fraser A.G., Kamath R.S., Ahringer J., and Plasterk R.H. 2003. A genome-wide screen identifies 27 genes involved in transposon silencing in C. elegans. Curr. Biol. 13: 1311.

Yan K.S., Yan S., Farooq A., Han A., Zeng L., and Zhou M.M. 2003. Structure and conserved RNA binding of the PAZ domain. Nature 426: 468.

Zamore P.D., Tuschl T., Sharp P.A., and Bartel D.P. 2000. RNAi: Double-stranded RNA directs the ATP-dependent cleavage of mRNA at 21 to 23 nucleotide intervals. Cell 101: 25 . 


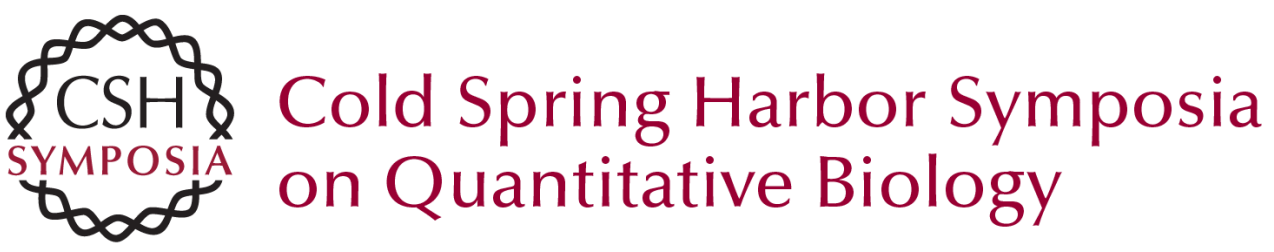

\title{
The Caenorhabditis elegans Argonautes ALG-1 and ALG-2: Almost Identical yet Different
}

\author{
B.B.J. TOPS, R.H.A. PLASTERK and R.F. KETTING
}

Cold Spring Harb Symp Quant Biol 2006 71: 189-194

Access the most recent version at doi:10.1101/sqb.2006.71.035

References This article cites 37 articles, 14 of which can be accessed free at: http://symposium.cshlp.org/content/71/189.full.html\#ref-list-1

License

Email Alerting Receive free email alerts when new articles cite this article - sign up in Service the box at the top right corner of the article or click here. 